\title{
The Specular Microscope: Its Impact on Laboratory and Clinical Studies of the Cornea
}

\author{
S A HODSON and E S SHERRARD
}

London

The specular microscope views objects illuminated from above. The objective lens acts additionally as the condenser lens. Light passes from inside the microscope out through the objective lens to arrive at a focus near the focal plane of the lens. If this position coincides with a reflecting surface, then the focussed light is reflected back through the objective lens and can be viewed, as usual, through the eye piece of the microscope. The principle of specular microscopy seems first to have been introduced in metallurgical microscopes but was independently utilised by David Maurice in the early 60s for his continued investigation into the physiology of the cornea. Its use in corneal research has been prolific and its advantages in this tissue are clear. Specular reflections of the epithelial surface and more particularly of the endothelial surface are readily obtained in this transparent tissue. Additionally, measurement of the separation between these two layers, the corneal epithelium and the corneal endothelium, may be made with great accuracy which makes the detection of fluid flows into and out of the corneal stroma particularly easy.

When I (SH) first went to work with David Maurice as his Research Assistant in 1966 at the Institute of Ophthalmology in London, my duties centred around developing studies with the specular microscope. Maurice had already developed movies of the endothelial cells and, amongst other assignments, I was to try to work out the significance of the specular appearances. The world's first corneal specular microscope was a monstrous machine. It consisted of an elaboration of iron girders and cross pieces strapped to which at various critical points were the lenses and light source of the system maximum experimental flexibility and minimum operational convenience. I added a $35 \mathrm{~mm}$ camera to the system and the world's first ever still photograph of corneal endothelium (a rabbit's) is shown in Figure 1. Later, Maurice developed his elegant dissection technique for mounting isolated corneas under the specular microscope. Shabtay Dikstein came to work in the laboratory and together they produced a classic paper showing how the specular microscope can be used to investigate corneal physiology. ${ }^{1}$ The use of the specular microscope in examining profiles or corneal endothelium has been most fruitful in clinical studies. This review will concern itself mainly with the role of the specular microscope in contributing towards our understanding of the water relations of the cornea and consequently of its transparency ${ }^{2}$ and also with the impact of the specular microscope on clinical studies.

\section{The Value and Limitation of the Corneal} Specular Microscope in Laboratory Studies

The usual preparation for laboratory studies consists of an isolated cornea perfused across its posterior surface with a suitable Ringer solution and covered on its anterior surface with silicone oil, with a refractive index near to that of corneal stroma, and mounted under the specular microscope for visual inspection. The microscope can be wracked up and down to focus sequentially upon the anterior epithelial/silicone oil interface which is usually shown as a bright reflection, the epithelial/stromal interface which usually 


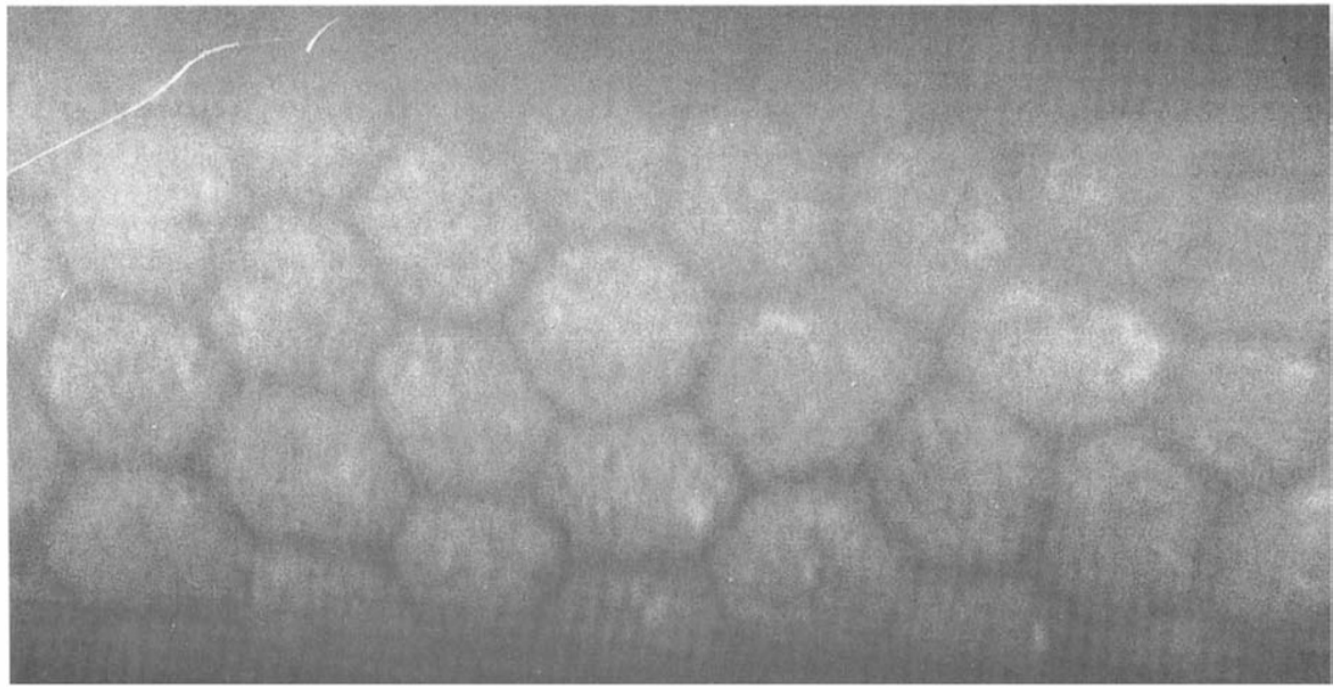

Fig. 1. The earliest photograph (November, 1966) of corneal endothelium taken with the specular microscope. Tissue was a fresh enuclated rabbit's eye $(x 1,000)$.

appears as a blue reflection, and the endothelial/ Ringer interface in which the profiles of individual cells are clearly visible (Fig 1). This reflection is from the posterior surface of the endothelial cells. Additionally, it is possible to collect low contrast (scattering) images from keratocytes as the corneal stroma is traversed. The preparation is the almost precise replication of the physiological state of the cornea in the open eye situation. In particular, although superficial silicone fluid prevents the loss of water from the anterior surface of the preparation, it is quite permeable to $\mathrm{CO}_{2}$.

There are, in general, three ways of estimating fluid flows into and out of the tissue. The oldest method is that of the "temperature reversal phenomenon". 3 Here the cornea, usually in the whole eye is refrigerated for a day when the corneal stroma swells and consequently increases the separation between the epithelium and endothelium. The isolated swollen cornea is then placed under the specular microscope and, on perfusion by a suitable Ringer at body temperature, is observed to thin back towards its original physiological thickness. ${ }^{1}$ One disadvantage of this preparation is that the endothelial cells, which are primarily responsible for maintaining corneal hydration, are not fresh. The second method introduced by Fischbarg, ${ }^{4}$ is to mount a fresh but de- epithelialised cornea under the specular microscope and superfuse this denuded anterior stromal suface with Ringer. The stroma swells. If, at some time, the superficial Ringer is replaced with silicone fluid then the corneal stroma is observed to thin, just as in the temperature reversal phenomenon, but this time with a fresh preparation. This technique could be justified only after it became clear that the epithelium had only a very minor role to play in regulating corneal hydration. ${ }^{5,6}$ The third method, less dramatic in its presentation but obviating the needs of either de-epithelialised or stored tissue, is to mount fresh cornea under the specular microscope. ${ }^{7}$ Nothing happens but, nevertheless, the equilibrium represents a dynamic balance between the endothelial pump and the continuous leak across the endothelium from the bathing Ringer into the stroma and any disturbance to this equilibrium can be sensitively detected.

The advantages of the specular microscope are that it is easy to use and is accurate. Consequently, there is very little disagreement in the literature from the various laboratories that have contributed to the pool of knowledge in this field. It clearly demonstrates the movement of fluid across the surface of the cornea and unambiguously validated earlier work $^{8}$ which had indicated that the endothelium was the 
regulating layer maintaining corneal hydration. The difficulty of specular microscopy work lies in its interpretation. For example, if the experimental protocol results in the cornea swelling, this can mean that we have either inhibited the endothelial pump or promoted the endothelial leak. There is even a third possible interpretation which is that we could have altered the stromal swelling pressure. So, although the preparation gives a good overall picture of the response of the system it is not analytical in indicating which of the several components. which together constitute the pump leak balance, is responsible for the observed response.

\section{The Model for Corneal Stasis}

The best description of the pump-leak balance in the physiological state is given, perhaps a little obscurely, in an appendix of a classic paper ${ }^{9}$ which states that at equilibrium, the relationship holds:

$$
\mathbf{J}=\frac{\omega \mathrm{SP}}{\sigma}
$$

Where $\mathbf{J}=$ the endothelial metabolic 'pump'

$\omega=$ endothelial permeability to the substrate of the metabolic pump

$\sigma=$ the endothelial reflection coefficient to that substrate

$\mathrm{SP}=$ stromal swelling pressure

$\omega \mathrm{SP}$

$\sigma \quad$ collectively and numerically represents the "leak".

By a variety of experimental designs, the specular microscope has contributed towards our understanding of three of these four parameters. Nevertheless, other techniques, which are not the subject of this review must be used to arrive at an unequivocal interpretation. As an aside, it can be mentioned that the two other main techniques which have been used to complement specular microscope studies are:

(a) electrophysiological, eg monitoring electrical activity and ion fluxes across endothelial stromal preparations, and

(b) fluid half chambers where, again, isolated endothelial stromal preparations are placed between two half chambers and fluid flows from the stromal side chamber to the endothelial chamber are observed.
In addition a variety of ways have been devised for measuring stromal swelling pressure.

With these other techniques the literature reports a much wider variety of observations than have been reported with the specular microscope. The reason for this diversity is associated with the technologically greater difficulty of the alternative techniques. For example, only one laboratory seems capable of measuring ion fluxes under conditions of short circuit. Similarly, fluid chamber flows are riddled with potential sources of error some of which are still reaching the literature. Recently, it has also become clear that methods for measuring stromal swelling pressure include determinations not only of the water potential in the stroma but include a rheological component which has no relevance to an understanding of the pump-leak relationship.

We shall use the "pump-leak" equation of Mishima and Hedbys 9 (equation 1 above) to define individualiy each of the four parameters of the pump leak equilibrium of the normal cornea and show how the specular microscope has made its contribution to their evaluation.

\section{Endothelial Reflexion Coefficient}

Reflexion coefficients result from the interaction of salt and water molecules as they pass across. They may be visualised as follows:

If a salt solution is forced through a membrane by a hydrostatic pressure and if the reflexion coefficient of that membrane to the salt is zero, none of the salt is reflected at the membrane and the whole solution passes through intact. If, however, the reflexion coefficient of the membrane to the salt is maximum, which is given a numerical value of 1 , then all the salt is reflected at the membrane and only pure, filtered water is driven across the membrane by the pressure. Solute/membrane interactions usually give reflexion coefficients $(\sigma)$ somewhere in the range $0-1$. If $\sigma=1$, classically the membrane is thought of as semi-permeable. If $\sigma=0$, the membrane is usually thought of as freely permeable. (A fraction value of $\sigma$ has no common description.)

Another way of visualising reflexion coefficient is osmotically. If a solute with reflexion coefficient of 1 is added to the solution on one side of a membrane then (subject to the water permeability, or hydraulic conductivity, of 


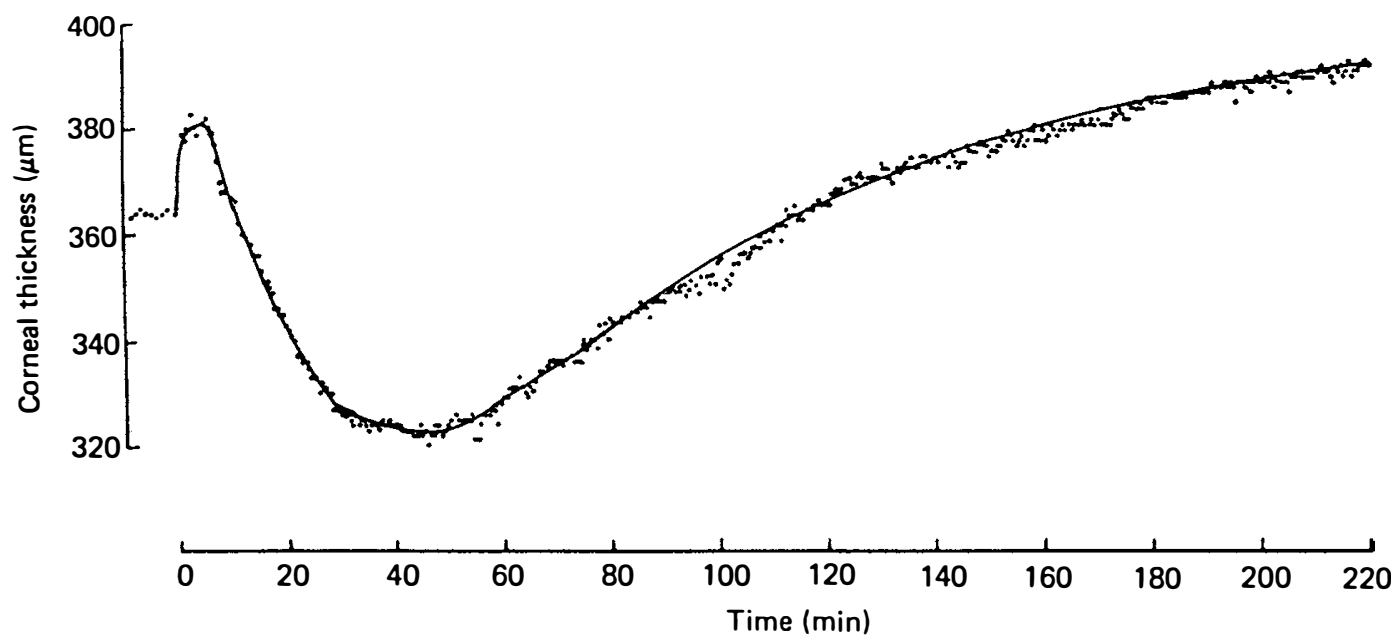

Fig. 2. At time zero, a pre-equilibrated cornea had $59 \mathrm{mM}$ raffinose added to the bathing Ringer whilst 61mM $\mathrm{NaCl}$ was substituted out. The continuous line is the best fit of three independent exponentials originating at time zero. Experiments such as these allow comparisons of the reflexion coefficients of corneal endothelium to $\mathrm{NaCl}$ and raffinose.

the membrane) a maximal osmotic flow of water will be observed to pass across the membrane. If a similar experiment is made with a solute which has a reflexion coefficient of zero, then.no fluid flow will be observed. Reflexion coefficients are the factors which modulate the molarity of solute to give the practical osmolarity of a solute across a particular membrane. Reflexion coefficients result from interactions between solute and solvent in any particular membrane.

The reflexion coefficient of corneal endothelium to salt has recently been shown to be about 1. Experiments were made under the specular microscope by substituting some of the salt in the Ringer solution with impermeable sugars such as Raffinose. ${ }^{10}$ The typical time course of corneal thickness changes are shown in Figure 2 which will be seen to have four distinctive phases. The first phase is represented by a horizontal line (pre-time zero in Figure 2) and represents a fresh rabbit cornea equilibrated in Ringer solution. At time zero a new solution is presented to the endothelial surface in which $61 \mathrm{mM} \mathrm{NaCl}$ in the Ringer solution is substituted by $59 \mathrm{mM}$ Raffinose. The initial corneal swelling represents the difference between the osmotic pressures of the removed $\mathrm{NaCl}$ and the added Raffinose. The third phase, which appears after the initial maximum increase in corneal thickness, represents the net efflux as $\mathrm{NaCl}$ diffuses out of the stroma into the Ringer and the fourth phase, after the minimum corneal thickness is reached, represents an influx of Raffinose from the Ringer into the corneal stroma. In reality, all these three processes are going on continually after the substitution is made and we observe manifested in the three phases after substitution the dominant process, ie that which is farthest from its equilibrium. When suitable mathematical treatment is applied to the data then the true osmotic inbalance between the substituted out $\mathrm{NaCl}$ and the added Raffinose (the first phase after substitution) can be properly assessed. It has been shown that initial equal osmotic concentrations of $\mathrm{NaCl}$ and Raffinose are required for a balance, which means that their endothelial coefficient are equal to each other and, in fact, both are about 1 .

These results are very interesting. They show corneal endothelium to act as a semi-permeable membrane with respect to salt, which seems in contradiction to the well known observations which indicate that corneal endothelium is readily permeable to salt. The authors noted that terminology used to describe epithelia is unsatisfactory in that corneal endothelium is experimentally both a leaky and semi-permeable membrane. Their explanation was that the inconsistency lies in the classical notion of a semipermeable membrane which is permeable only 
to the solvent, water, and its more modern description as a membrane with a solute reflexion coefficient of 1 . This study indicated that a value of 1 for the reflexion coefficient does not require an impermeable solute and they propose an alternative nomenclature for permeable and semi-permeable membranes to be called 'bi-permeable' membranes. They also suggested that water flows across the endothelium passing mainly through the cells whereas salt can only diffuse between the cells and cited the evidence of Hodson and Wigham, " in support of their proposal.

In this application of specular microscopy the experiments have lead to conclusions about the detailed routes of molecular passage across the endothelium.

Because this study indicates that reflexion coefficient is 1 in the pump-leak balance described in Equation 1, then it can be ignored and the equation re-written as:

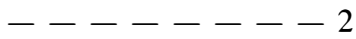

$$
\mathbf{J}=\omega \mathrm{SP}
$$

\section{Endothelial Permeability}

Endothelial permeability is not readily measured with the specular microscope, but is easily measured if endothelial/stromal preparations are mounted between two half chambers and the rate of passage of the solute (usually in a radioactive form) is monitored. As the permeability of the endothelium is about equal to the permeability of the corneal stroma, it is important to repeat the flux experiments on the de-endothelialised preparation and calculate the endothelial permeability by the difference relationship given in Hodson and Wighiam."

Specular microscope observations can indicate only gross changes in endothelial permeability under experimental conditions. ${ }^{12}$ If the cornea swells at more than $40 \mu / \mathrm{hr}$ then it can safely be assumed that not only has the endothelial pump been switched off (which without any change of endothelial permeability results in a swelling rate of about $40 \mu / \mathrm{hr}$ ) but that endothelial permeability has been increased. The classic study was that which showed that in a calcium deficient Ringer, endothelial permeability is increased. ${ }^{13}$

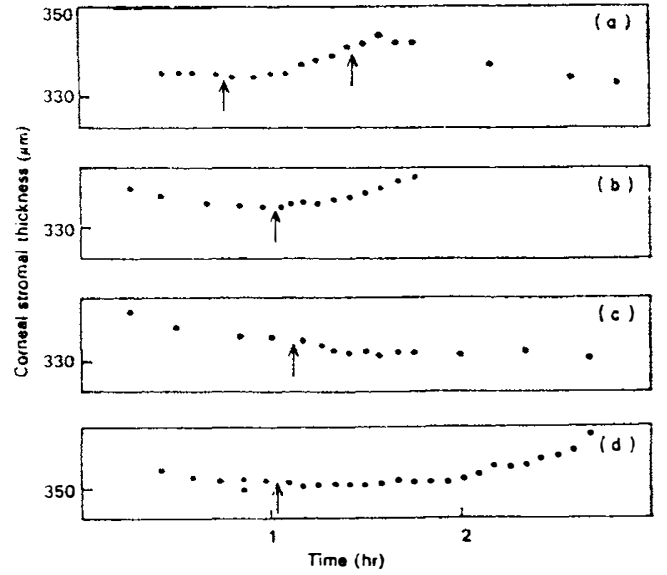

Fig. 3. Near equilibrated corneas bathed in bicarbonate Ringer are substituted at the first arrow by iso-osmotic Trs buffered Ringers including (a) $4 \mathrm{mM}$ bicarbonate (b) $8 \mathrm{mM}$ bicarbonate (c) $12 \mathrm{mM}$ bicarbonate and (d) $24 \mathrm{mM}$ bicarbonate. In these experiments, swelling is induced by inhibiting the bicarbonate pump. The swelling is reversible (second arrow (a)).

\section{The Endothelial Pump}

If the bicarbonate concentration in the Ringer is reduced to values below $12 \mathrm{mM}$, then the cornea swells (Fig 3) and the swelling is completely reversible upon the re-introduction of a physiological concentration of bicarbonate. ${ }^{14}$ This basic observation underlies a very simple phenomenon. The endothelial pump consists entirely of a metabolically coupled flux of bicarbonate ions. ${ }^{15}$ About two thirds of the bicarbonate flux is trans-cellular conversion and the remaining one third is generated by the intracellular conversion of $\mathrm{CO}_{2}$ to bicarbonate ions via an enzyme carbonic anhydrase. ${ }^{16}$ The explanation of the behaviour of the cornea on substituting bicarbonate out of the bathing Ringer is that the pump is starved of substrate and reduces to a level corresponding to the new external bicarbonate concentration. The leak is unchanged. Consequently the cornea swells. It is a remarkable phenomenon that this method of turning off the pump (substrate deprivation) in no way affects the viability of the endothelial cells themselves. The endothelial bicarbonate pump can be thought of as entirely to the benefit of the stroma, in reducing its hydration and maintaining its transparency, and as a burden on the endothelial cells. One interesting 
consequence of this way of looking at the endothelial pump is that it was observed that the endothelial cells, per se, are observed to survive a longer time in a better state in vitro, if the storage medium contains no bicarbonate. ${ }^{17}$ So far, this interesting experimental finding has not been utilised clinically.

\section{Corneal Swelling Pressure}

Until recently the specular microscope had no known role in measuring corneal swelling pressure. The standard method for measuring swelling pressure had been to allow corneal stroma to swell between two rigid mechanical plates, one of which incorporates a pressure transducer. Swelling pressure was calculated from the equilibrium force recorded at the transducer. ${ }^{18}$ It has been apparent for several years that this method of measuring swelling pressure incorporates not only the chemical potential of water in the stroma, which is the physiological important pressure, but also a rheological component resulting from the lateral distortion of the stroma as it presses against the mechanical plates. ${ }^{19}$ For some years, a method has been sought to measure swelling pressure osmotically which required the presence of an osmotically active macromolecule in the Ringer bathing the corneal surface and it was essential that the macromolecule did not penetrate into the stroma. Polyethyleneglycol (PEG), average M.Wt $10 \mathrm{kD}$ fulfils this requirement. The first series of experiments using, in part. the specular microscope have now been completed ${ }^{20}$ and can be visualised as follows:

The cornea is mounted under the specular microscope and perfused with Ringer. When the cornea has a stable thickness, the pump is completely inhibited with $10^{-4} \mathrm{M}$ ouabain and intra-ocular pressure is lowered towards zero. Fresh Ringer is introduced with $2-8 \%$ PEG and the corneal stroma is observed to de-swell (in $8 \%$ PEG) or swell (in 2\% PEG) to a new equilibrium value which can be maintained indefinitely. This stromal hydration incorporates the swelling pressure which exactly balances the osmotic pressure of the PEG in the external Ringer. In fact, the experiments are much simpler because it turns out that PEG does not penetrate Descemet's membrane and so the corneal endothelium can be entirely dispensed with, and the complex Ringer needed to maintain corneal endothelium can be substituted by a simple solution of $0.9 \%$ saline, with the same results. The osmotic pressure of the PEG needs to be calibrated and this is done as follows: The de-epithelialised cornea is mounted under the specular microscope and overlaid on the bare antierior surface of the stroma with $0.9 \%$ saline. The endothelial surface is perfused with $0.9 \%$ saline including (say) 2\% PEG. Hydrostatic pressure is applied to the endothelial surface until it is observed that there is no fluid flow across the preparation either into the overlaid Ringer or out of it. At this point, because Descemet's membrane acts as an ideal semipermeable membrane to $10 \mathrm{kD}$ PEG, the osmotic pressure of the PEG is in balance with the hydrostatic pressure head on the posterior surface of the preparation.

These values of determining corneal swelling pressure by an osmotic method, utilising, at least in the development stages, the specular microscope, indicate that corneal swelling pressure is about $25-30 \%$ lower than values taken with mechanical devices. It seems reasonable to assume that the difference between the two methods of measuring swelling pressure results from unwanted (for these purposes) rheological components included in the mechanically determined values.

\section{The Specular Microscope in the Clinic}

Although most modern clinical specular microscopes (SM) are fitted with a pachometer and corneal thickness can be measured reasonably accurately, the SM is used primarily to view and photograph the corneal endothelium and to monitor changes in its morphology.

Before SM the morphology of the normal human corneal endothelium could be studied only in donor eyes, the age and condition of which is arbitrary, and of the abnormal endothelium in corneal buttons excised at keratoplasty, in which only the endothelial 'corpse' is represented with little evidence of the 'mode of death' as it were. The SM permits the repeated examination of the endothelium in essentially any selected eye in almost any condition. The only requirement is that the overlaying corneal tissues be reasonably transparent.

With the development of the large field SM which includes approximately one square $\mathrm{mm}$ of 
actual endothelium in each field of view (Fig 4), there came an incidental, alternative mode of imagery, known as the relief mode ${ }^{21}$ or indirect specular microscopy, ${ }^{22}$ in which irregularities of the posterior corneal surface are thrown into apparent relief (Fig 5). The relief image appears in the upper part of the field of view and is the result of unilateral (from below) retroillumination of the cornea with light reflected from the lens or iris surfaces. Hence posterior excrescences, eg swollen cells, guttata and keratic precipitates (KP), are light inferiorly and shadowed superiorly, while the illumination of pits into the posterior corneal surface is reversed. The normal surface is smooth and has no relief image.

By direct viewing with the SM, using both specular and relief modes, an overail impression of the condition of the endothelium can be established immediately. The features looked for are the regularity of the endothelial mosaic and the overall sizes of the component cells in relation to the patient's age, the presence of bizarre cell shapes, intracellular vacuoles, and extraendothelial features such as corneal guttata, inflammatory cells and pigmented KP. From the photomicrographs detailed analyses of various parameters of the endothelium can be made, eg the number of cells per unit area can be estimated, the size (surface area) of individual cells, the number of sides of cells, cell perimeters, diameters, etc can be measured and the ratio of cells of different forms within the mosaic can be established.

Specular microscopy has allowed the study of the natural fate of the endothelium in ageing and the influences of many diseases and insults, in the living state.

\section{The normal human endothelium}

There have been several studies ${ }^{23-28}$ of the normal human corneal endothelium and there has been variety in the findings. This is probably because different specular microscopes and subjects of different age groups have been employed. Nevertheless, some constant features have emerged and most of these are related to a loss of cells from the mosaic throughout life. Some studies find that the loss is continuous while others suggest that there are phases of peaking and plateauing. All studies show that, while the cell population density (CPD), which is usually expressed as cells $/ \mathrm{mm}^{2}$, reduces with increasing age, there is much variation within any age group. Similarly the degree of irregularity of the mosaic varies greatly. This means that in any longitudinal study of the response of the endothelium to insult it is necessary to establish the norm for each individual eye beforehand. Since, however, the CPDs of eyes of a pair are the same, ${ }^{23.27}$ one can often be used as the control for the other in retrospective investigations. In the study of bilaterally diseased endothelium the mean CPD for the individual's age group has to suffice as the presumed starting point.

In infants of less than one year old the corneal endothelium is composed of small similar cells giving a very regular mosaic ${ }^{28,29}$ (Fig 4). The mean CPD is close to 4,500 cells $/ \mathrm{mm}^{2}$ and the range from 5,500 to 3000 cells $/ \mathrm{mm}^{2}$. The cells are polygonal, mainly hexagonal, but the angles are rounded to give an almost circular shape. Pairs of 'twinned' cells which have no visible interposed cell border and might be mitosing, are scattered throughout many examples. There is an apparent mean loss of $26 \%$ of the cells during the first year of life. This, however, is probably due to corneal growth with mitoses, if any, failing to keep pace with the increasing corneal area.

The endothelial mosaic remains regular until the age of about 25 years even though the reduction of CPD continues. Twenty six percent of the mean at one year old are lost between the ages of one and 12 years and half of this is accomplished before age five. This early loss is no doubt apparent being, at least in part, due to further corneal growth; once growth has ceased, cell loss is real.

In early adulthood the mean CPD is in the region of 3,000 cells $/ \mathrm{mm}^{2}$, in the fourth decade it is about 2500, and in old age around 2000 cells $/ \mathrm{mm}^{2}$. The loss of cells results in the lateral spread of the survivors which increase in angularity and clarity as seen by SM. Although in about half the population the remaining cells enlarge to similar proportions and so maintain a regular (or homomegethous) mosaic pattern (Fig 6) even into old age, in the other half, cells enlarge unevenly to result in an irregular (or polymegethous) mosaic (Fig 7). The polymegethous endothelium, in which more cells enlarge to larger sizes with ageing, apparently fares less well than the homomegethous endothelium on insult. ${ }^{30}$ 


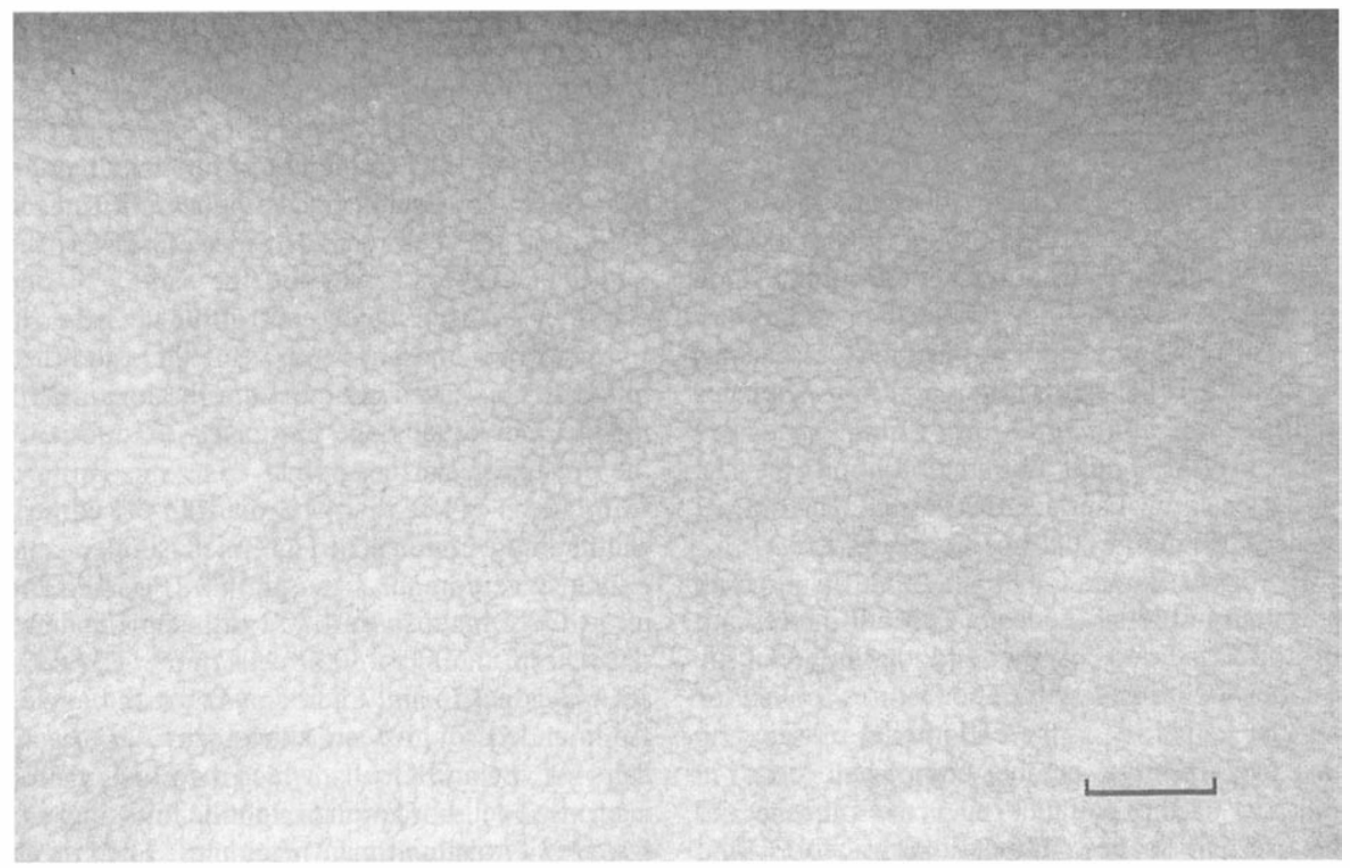

Fig. 4. Specular photomicrograph of corneal endothelium of six month old child. The area of actual endothelium in the picture is approximately $1 \mathrm{~mm} .^{2}$ The cells are small $\left(4800 / \mathrm{mm}^{2}\right)$ and the mosaic is very regular. Bar $=$ $0.1 \mathrm{~mm}$.

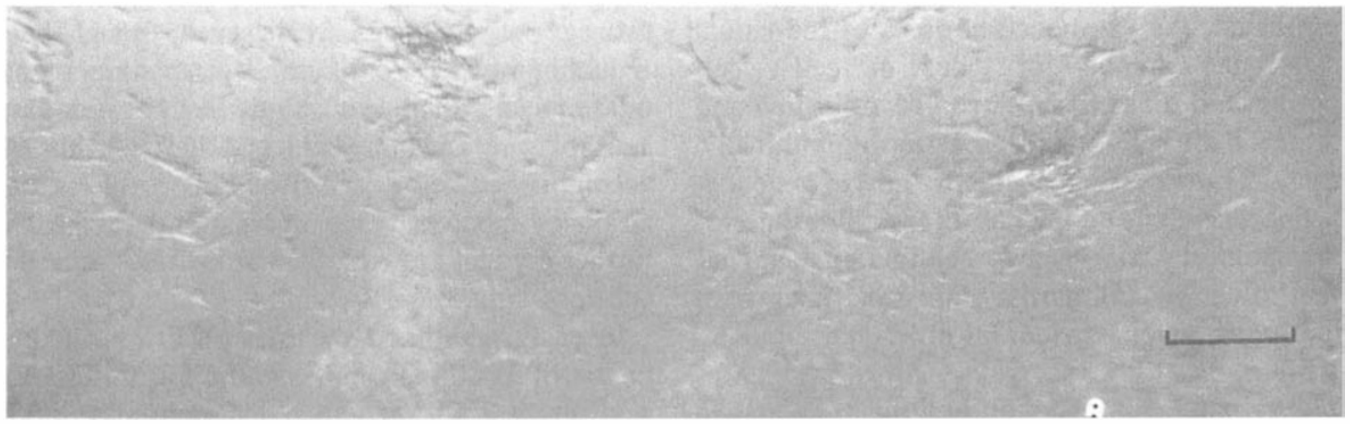

Fig. 5. Relief photomicrograph of the posterior corneal surface in a case of heterochromic cyclitis. Numerous inflammatory cells, some clumped together, are revealed. Bar $=0.1 \mathrm{~mm}$.

At the age of about 25 years a further corneal feature occurs which, although it does not concern the endothelium directly, does greatly facilitate its study. When the cornea is applanated, as with a contact SM, the posterior corneal surface is thrown into a number of gentle undulations. These form in a series of rings concentric with the centre of the cornea. They have been termed the posterior corneal rings (PCRs). ${ }^{31}$ Each appears as a pair of parallel, featureless, dark bands separated by a thin streak of visible endothelial cells (Fig 6). The diameter of the innermost PCR is approximately $3 \mathrm{~mm}$ and the rest, about 11 in all, extend out to the limbus. Although the PCRs are an artefact of corneal distortion and are not naturally present, they form in the same places and to the same patterns in the same cornea at the same pressure of applanation on different occasions. Hence they provide an intrisic target system in relation to 


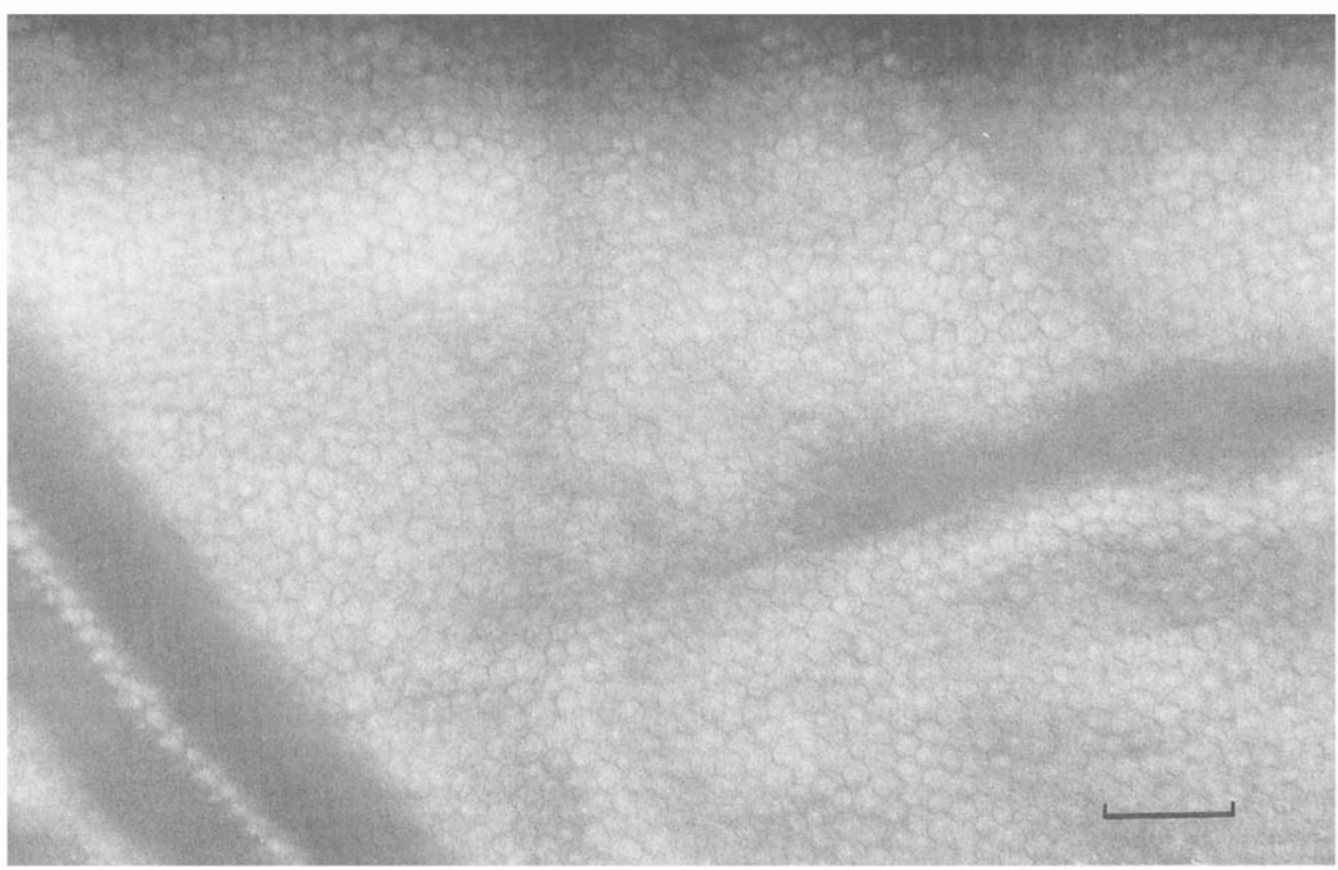

Fig. 6. Specular photomicrograph of corneal endothelium from a 40 year old man. The cells are similar in size and shape (homomegethous). 2267 cells $/ \mathrm{mm}^{2}{ }^{2}$ A portion of a PCR crosses the lower left corner of the picture. Bar $=0.1 \mathrm{~mm}$.

which any area, or even individual cell, of the endothelium can be repeatedly relocated. ${ }^{32}$ This facility adds accuracy to any study of the endothelium. Moreover, in certain corneal diseases the PCRs are characteristically distorted and in some conditions are present in children. They have, therefore, some diagnostic value.

\section{The Endothelium in Disease}

Several diseases of the cornea primarily involve the endothelium. The irido-corneal endothelial (ICE) syndrome, posterior polymorphous dystrophy (PPD), and Fuchs's endothelial dystrophy are being studied, and observations of the effects of infections and inflammation have been recorded.

The ICE syndrome is a non-familial, usually unilateral condition which affects the cornea, the iris and often the angle. Glaucoma and corneal decompensation are blinding sequele. An anomoly of the corneal endothelium has long been suspected as the fundamental factor in the ICE syndrome but, before specular microscopy, the material available for study was limited to the minute specimens provided at trabeculectomy and the 'burnt out' corneal discs from keratoplasty. Specular microscopial studies of the affected in vivo eyes have so far given no conclusive answers as to the basic cause of the disease, but several hitherto unknown features of the endothelium, which can be related to other clinical factors, have been discovered. For example, four indentifiable variations of endothelial pathology are found. ${ }^{33}$ Two of these are early with respect to the appearance of the first signs and symptoms of the disease and each 'progresses' into one of the others. All are characterised by the presence of abnormal cells (ICE-cells) which show a reversal of the normal cell image (Fig 8). The outlines of ICE-cell appear lighter than the cell body and there is usually a central highlight. In one early variant, termed disseminated-ICE, the overall endothelial image is poorly defined, the cells are generally enlarged and ICE-cells are scattered throughout the mosaic. Within a short time (less than two years), the whole endothelium is converted to or replaced by ICE-cells which now form 'ICE-tissue' and a second variant is formed. This is total ICE and can remain 


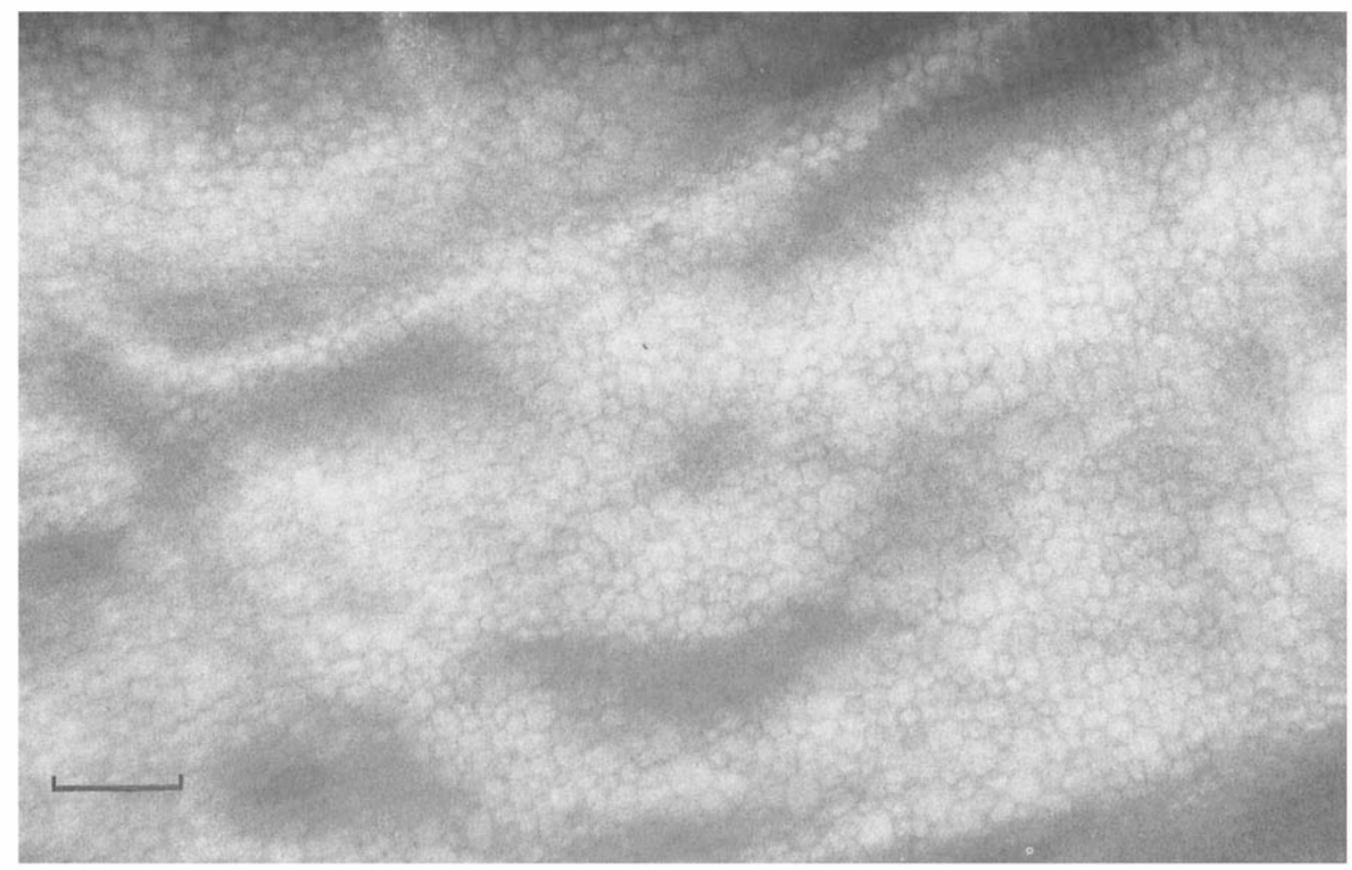

Fig. 7. Specular photomocrograph of corneal endothelium from a 72 year old man. The cells are dissimilar in size (polymegethous). 2309 cells $/ \mathrm{mm} .^{2} \mathrm{Bar}=0.1 \mathrm{~mm}$.

unchanged for many years. Intraocular pressure (IOP) is elevated in $82 \%$ of cases of disseminated/total ICE. Thus, the finding of either by SM indicates potential glaucoma if not already present. Even when IOP is satisfactorily controlled, many of these corneas become oedematous and eventually decompensate. On the other hand, many do not.

The change from disseminated - to total - ICE appears to be an alteration of preexisting endothelial cells to ICE-cells.

In the other variants only a portion of the endothelium is 'replaced' with ICEtissue; ${ }^{33,34,35}$ these are the 'subtotal' variants. In the earlier form (Fig 8) the remaining endothelial cells are extremely small with a CPD equivalent to that of babies of less than a year old and the variant is called subtotal- $\operatorname{ICE}(+)$. The two tissue types meet at a clearly defined interface with the endothelial cells adjacent to the ICE-tissue being elongated parallel to the junction. It appears as though the cells are being compressed into an increasingly smaller area. In the later form, the remaining endothelial cells are enlarged, often greatly with a CPD as low as 700 cells $/ \mathrm{mm}^{2}$, and the variant is termed subtotal (-). The ICE/endothelium junction is virtually indistinguishable and the two tissue types merge. In one recorded case subtotal $\operatorname{ICE}(+)$ has been seen to change to subtotal $\operatorname{ICE}(-),{ }^{33}$ and it is tentatively assumed that this usually occurs. The subtotal variants are rarely (14\%) associated with elevated IOP. Nevertheless, the corneas can become oedematous and some require keratoplasty.

There are two possible but opposing interpretations of the morphology of the subtotal variants; (1) that the endothelium reproduces excess cells and so compresses itself and part metamorphosis to ICE tissue, (2) that the ICEtissue is invading the posterior corneal surface from elsewhere.

The possible change of subtotal-ICE $(+)$ to subtotal-ICE $(-)$ may be the withdrawal or regression of this alien tissue and the expansion of the compressed endothelium, with the mechanical loss of many cells, to colonise the area vacated.

The origin and nature of the ICE-cell is still unknown and clearly much work remains to be done. 


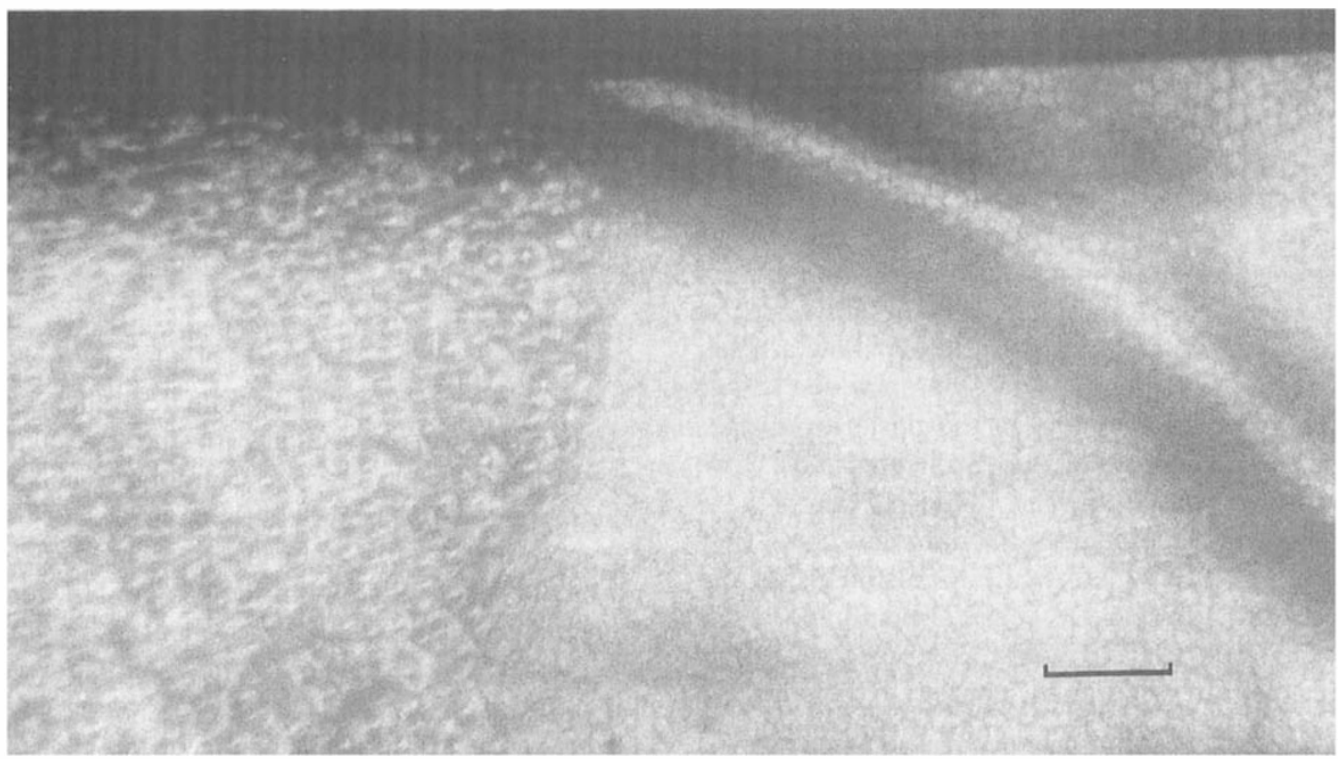

Fig. 8. Specular photomicrograph of posterior corneal surface in a case of irido-corneal endothelial syndrome - subtotal-ICE(+). To the right side the endothelium is composed of extremely small cells $\left(4086 / \mathrm{mm}^{2}\right)$, to the left it is "replaced" with ICE-tissue (2465 ICE-cells $\left./ \mathrm{mm}^{2}\right)$. Bar $=0.1 \mathrm{~mm}$.

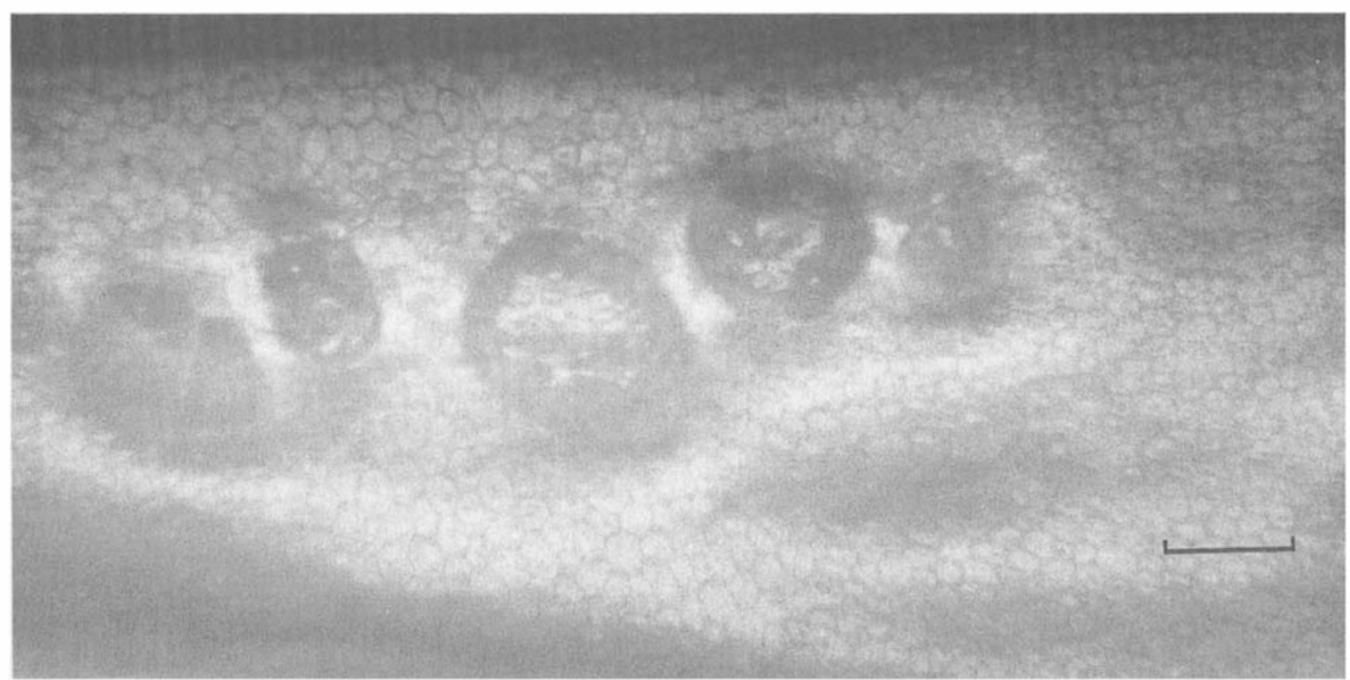

Fig. 9. Specular photomicrograph of posterior corneal surface in a case of posterior polymorphous dystrophy (vesicular). The endothelial cells are enlarged close to the dark, circular, 'vesicular' lesions. Overall cell count $=1383$ cells $/ \mathrm{mm} \cdot{ }^{2}$ Bar $=0.1 \mathrm{~mm}$.

Posterior polymorphous dystrophy shows autosomal dominant inheritance and is probably congenital. Fundamentally it appears to be a failure of all or part of the endothelium to secrete the neonatal, posterior nonbanded layer of
Descemet's membrane. It is usually not blinding but is of considerable interest because there is evidence that it is closely related to the ICE syndrome. Indeed, in extreme cases it shows similar changes in the cornea, iris and angle. ${ }^{36}$ 
Since affected corneas usually remain clear, histopathological material is extremely rare and $\mathrm{SM}$ is an ideal method with which to study it.

Earlier studies of PPD with the slit lamp found that it presents in three different forms. ${ }^{37}$ In vesicular PPD there are one to several small, transparent, blister-like 'vesicles' at the level of Descemet's membrane. Each is set in a ring of opacity. They usually occur bilaterally and may be scattered or grouped and often show a linear arrangement. In band PPD there are one or two shallow linear troughs in the posterior surface of, usually, one cornea. Each appears as two opaque, parallel ridges bordering an area of roughened Descemet's membrane. Often this form of PPD is difficult to distinguish from neonatal splits in Descemet's membrane but is recognised as PPD by the presence of typical vesicles elsewhere in the cornea, in the other eye or, indeed, in another family member. Diffuse PPD affects a large area or all of the posterior corneal surface in one or both eyes and is accompanied by iris changes and elevation of IOP in some cases. It too is recognised as PPD by the presence of vesicles elsewhere in the family. This form often is blinding but seems to be relatively rare. So far as can be determined histopathologically from corneal buttons removed at keratoplasty, and which represent only the end stages of the disease, the prenatal, banded layer of Descemet's membrane is complete but the postnatal, posterior layer is not. The endothelium is composed of deformed, attenuated cells or replaced by multilayered epithelium-like cells. ${ }^{38}$

Specular microscopy fails to recognise multilayering or epithelial characteristics of the endothelium. Instead it reveals in vesicular/band PPD endothelial cells which are usually enlarged in the vicinity of the lesions but of more normal size distant from them. The CPD is reduced. The affected eyes of children show PCRs. Vesicles appear as dark rings "enclosing" endothelial cells (Fig 9), and bands appear as dark, parallel trans-corneal tracks with enlarged cells and guttata between them. In the relief mode vesicles appear as shallow depressions, and bands as shallow trenches, into Descemet's membrane. It seems possible that both forms represent localised maldevelopment of Descemet's membrane with the subsequent failure of endothelial cells to adhere to the abnormal scaffolding it provides; hence the low CPD. Possibly diffuse PPD is to be regarded as an extended form of band PPD with large areas of abnormal scaffolding with the result that the CPD of the endothelium rapidly reduces and the cornea decompensates.

Specular microscopy of Fuchs's dystrophy possibly adds little more to the understanding of the condition than can be gleaned with the slit lamp. However, one study ${ }^{39}$ claims to have documented progressive morphological changes of the characteristic guttata. In the specular image these appear as dark circular patches which range in size from less than one to five or six endothelial cell equivalents. Their size presumably depends upon their 'age'. In the relief mode guttata appear as small posterior excresences, with domed or indented apices. The number of guttata varies greatly being few and located just inferior to centre of the cornea in early cases (ie in young individuals), and many in advanced cases where they are confluent just below centre and dilute out towards the periphery. Endothelial cells cannot be seen by SM on the guttata but, if space allows, are visible between them. Some observers report that the cells are always enlarged but personal experience is that this is not so in some, even advanced, cases.

The specular and relief images of the posterior corneal surface in inflammatory conditions, eg heterochromic cyclitis, are dramatic but not necessarily very instructive. The endothelial mosaic is usually peppered with small, clearly defined black spots and there are occasional large, discrete dark areas. The relief mode reveals that the former are small inflammatory cells, often united by long, thin cytoplasmic processes (Fig 5), and the latter are conglomerations of inflammatory cells - the so-called mutton fat KP. The primary interest in $\mathrm{SM}$ of such cases has been that they assist in the interpretation of the specular images seen in cases where the slit lamp findings are not obvious. Longitudinal SM studies show that the larger KP remain unchanged in position, size and shape for many years.

Similarly the pigmented KP encountered after disturbance of the iris tend to remain 'fixed' in position, but they do round up and apparently sink into the endothelium. 


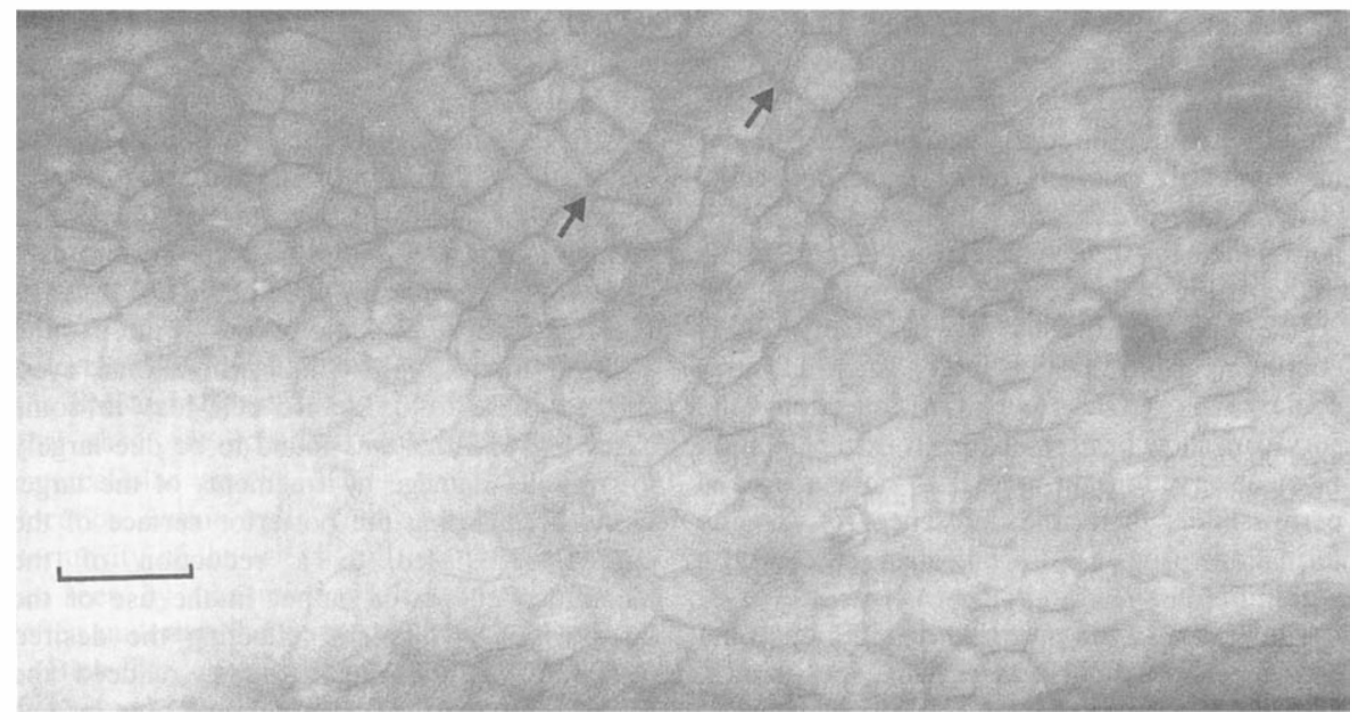

Fig. 10. Specular photomicrograph of posterior corneal surface in a case of 'endothelialitis'. The cells are greatly enlarged (395/ $\left.\mathrm{mm}^{2}\right)$, many are of bizarre shapes and rosette formations are present indicating current cell loss. Arrow $=$ centre of rosette. Bar $=0.1 \mathrm{~mm}$.

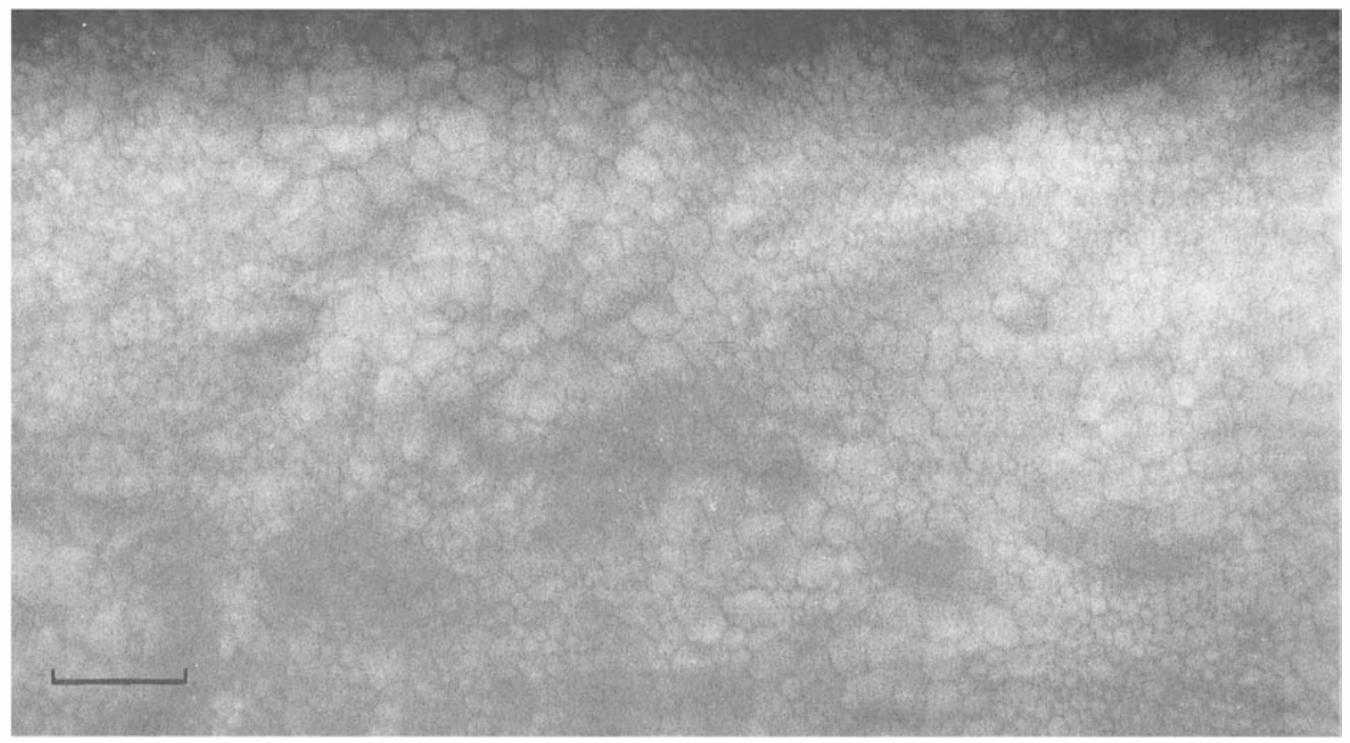

Fig. 11. Specular photomicrograph of posterior corneal surface in long term (25 years) PMMA contact lens wearer. The image is poor because of concurrent 'wavyness' of the surface. The cells are clumped into two populations - very large $\left(894 / \mathrm{mm}^{2}\right)$ and very small $\left(4140 / \mathrm{mm}^{2}\right)$. Overall cell count $=2332 \mathrm{cells} / \mathrm{mm} .^{2}$

\section{The Injured Endothelium}

Specular microscopy has been extensively used in longitudinal studies of the effects upon the corneal endothelium of a variety of modern anterior segment procedures, it has become an integral part of any clinical trial of a new innovation. Injury to the non-replicating endothelium results in the loss of cells and recolonisation of the resulting spaces by spread of the surviving cells. At first, cells in the region 
of damage are mishapen but, after a minimum time of three months, hexagonality becomes the rule. Most corneal grafts of long standing, which initially suffered circumferencial cutting injury, have regularly enlarged, mostly hexagonal cells. After cataract extraction cell size is graded across the back of the cornea with enlarged cells in the region of the wound to almost normal size at the opposite limbus. ${ }^{27}$ When cell loss is continuing from chronic injury, such as intraocular lens (IOL) touch or infection, the survivors show bizarre shapes. If extrapalotation from observations in animal to human eyes is permissible, then the presence of rosette formations (Fig 10) is indicative of cell loss within the last few hours. ${ }^{40}$

The effects of the insertion of IOLs upon the corneal endothelium was perhaps the greatest stimulus to clinical SM. Many studies showed that endothelial cells were lost per- and/or postoperatively. ${ }^{41}$ This led to modifications of the design and materials used in the manufacture of the IOLs and to changes in surgical technique. Endothelial protective agents, such as Healon and hydroxymethylcellulose were introduced. Further SM studies showed that each was as good as the other in protecting the endothelium from mechanical touch damage during IOL insertion and that neither, unlike air in the anterior chamber, embarrassed the delicate cells. $^{42}$

In many of the IOL studies, cataract extraction without an IOL served as the control, and some interesting observations ensued. For example it was found that the endothelium of the aphakic eye loses cells with ageing faster than in normal eyes. $^{27}$

The controversial operation of radial keratotomy initially greatly weakens the cornea and puts the endothelium at risk of mechanical distortion. However, SM investigation finds that apart from early, temporary endothelial changes, there is insignificant damage even in the long term. ${ }^{43}$

It was observed with the slit lamp that after almost any surgical procedure of the anterior segment, but especially cataract extraction, that the posterior corneal surface was criss-crossed with fine white lines. ${ }^{44}$ It was suggested that these "snail tracks" represented a considerable loss of endothelial cells. ${ }^{44}$ In vivo SM studies showed that, although there were some morpho- logical changes of the endothelium within some of the tracks, the actual loss of cells was minimal. ${ }^{45}$

It is reasonable to anticipate damage to the endothelium during various ocular laser procedures. In the early days of the use of the neodymium: YAG laser for posterior capsulotomy and iridotomy endothelial lesions were reported. ${ }^{46}$ Specular microscopy with parallel electron microscopial studies in animal eyes, showed these to be severe cell loss in some cases, ${ }^{46,47}$ and this was found to be due largely to 'missile' damage by fragments of the target tissue bombarding the posterior surface of the cornea. This led to a reduction of the recommended power output in the use of the laser which, while still effecting the desired disruption of the target tissue, reduced the endothelial trauma. Nevertheless, some lesions with characteristic SM appearance and arrangement still occurred. It was noticed that the distribution of these lesions mimiced that of the gas bubbles that form in the aqueous humour on photodisruption and float superiorly, eventually to adhere to the posterior corneal surface. It has been assumed that these bubbles in some way cause injury to the endothelium. ${ }^{47}$

Laser whose mode of action is heat absorption do not damage the endothelium providing the target tissue is sufficiently distant from the cornea.

Morphological changes in the corneal endothelium of contact lens wearers have been reported by several specular microscopists. The first was the appearance of small, dark, transient spots which have been termed 'blebs'. ${ }^{48}$ Blebs, which are usually smaller than cells and may appear to be within or between cells, and are sometimes clumped, are irregular in shape and distribution, and their occurrence is usually accompanied by loss of clear focusing of the entire endothelial mosaic. They appear and disappear, without visibly changing the cells, to a repeatable time scale. The first blebs appear within five to 10 minutes of insertion of the lens, their number increases gradually and peaks at between 15 and 20 minutes at a level which is reproducible in, yet variable among, individuals, and differs according to the type and thickness of the lens used. If the lens remains in place, the blebs gradually fade over a 60 to 90 minute period, and if the lens is removed they disappear 
in about five minutes. When the lens is repeatedly applied to the eye, blebs appear in different locations on each occasion. 49,50 According to some observers the blebbing response diminishes with repeated lens insertion over a long period of time, as in contact lens wearers, and it is assumed that this indicates that the cornea becomes accustomed to lens wear. ${ }^{49}$

The nature of the bleb has not been determined. However interpretation based upon the SM and the negative relief images suggests that they are localised enlargements of the intercellular spaces. Their frequent apparent location within cells could be related to the tortuosity of the lateral cell membranes which, as seen by transmission electron microscopy, often underlap the centre of the cell.

Bleb-like changes occur during periods of prolonged eye closure, eg. sleep and may, therefore, be regarded as harmless. It has been argued, however, that additional blebbing, as with contact lenses, could overtax the endothelium. ${ }^{51}$

It seems that blebs arise in the endothelium in conditions of relative hypoxia and the accumulation of lactate in the cornea and/or the aqueous humour.

A change of more acute concern related to contact lens wear is an unusual increase in the polymegethism and pleomorphism of the endothelial cells. This was first noted in subjects who had worn PMMA lenses for several years ${ }^{52}$ and was later shown to occur within a few years of the use of daily and extended wear soft lenses. $^{53}$ It appears that the CPD does not diminish as compared with non wearers but that the endothelium is composed of clumps of smaller and larger than average cells ${ }^{51,54}$ (Fig 11). Irregularity, or wavyness of the posterior cornal surface accompanies these changes. Cessation of lens wear does not result in the return of the normal endothelical mosaic. ${ }^{53}$

Because similar morphological changes to not occur with lenses of high oxygen transmissability (silicone elastomer), ${ }^{55}$ it is considered that hypoxia is, again, the root cause. The significance of the changes remain unknown and, perhaps, somewhat worrying even though no functional abnormalities can be detected. ${ }^{56}$

Specular microscopy has made an important contribution to the quality control of donor corneas for keratoplasty. It was initially used in this context to assess animal corneas stored by experimental methods by revealing morphological and functional changes in the endothelium. It essentially eliminated the need for experimentation with living recipient animals. Now it has become the only method to evaluate human donor corneas. It provides a means for detailed examination of the morphology of the endothelium before and during banking and just prior to transplantation.

\section{References}

'Dikstein S and Maurice DM. The metabolic basis to the fluid pump in the cornea. J Physiol 1972; 221: 29-41.

${ }^{2}$ Maurice DM. The structure and transparency of the cornea. J Physiol 1957; 136: 263-86.

${ }^{3}$ Davson H. Some considerations on the salt content of fresh and old ox cornea. Br J Ophthalmol 1949; 33: 175-82.

${ }^{4}$ Fischbarg J. Active and Passive Properties of the Rabbit Corneal Endothelium. Exp Eye Res 1973; 15: 615-38.

${ }^{5}$ Riley MV. The role of the epithelium in control of corneal hydration. Exp. Eye Res. 1971; 12: 128-37.

${ }^{6}$ Klyce SD. Enhancing fluid secretation by the corneal epithelium. Invest Ophthalmol 1977; 16: 958-73.

${ }^{7}$ Hodson SA. The regulation of corneal hydration by a salt pump requiring the presence of sodium and bicarbonate ions. J. Physiol 1974; 236: 563-77.

${ }^{8}$ Mishima $\mathrm{S}$ and Kudo $\mathrm{T}$. In vitro incubation of rabbit cornea. Invest Ophthalmol 1967; 6: 329-39.

${ }^{9}$ Mishima S and Hedbys BO. The Permeability of the Corneal Epithelium to Water. Exp Eye Res 1967; 6: 10-32.

${ }^{10}$ Hodson SA and Lawton DM. The Apparent Reflexion Coefficient of the Leaky Corneal Endothelium to Sodium Chloride is about One in the Rabbit. J Physiol 1987; 385: 97-106.

${ }^{11}$ Hodson SA and Wigham CG. The Permeability of Rabbit and Human Corneal Endothelium. $J$ Physiol 1983; 342: 409-19.

${ }^{12}$ Greene K. Active Control of Corneal Thickness. Life Sciences 1966; 5: 2309-14.

${ }^{13}$ Mishima S, Kaye GI, Takahasi GH, Kudo T and Trenberth SM. The function of the corneal endothelium in the regulation of corneal hydration. The Cornea, ed Langham ME 1969; 207-35.

${ }^{14}$ Hodson SA. Why the Cornea Swells. J Theor Biol 1971; 33: 419-27.

${ }^{15}$ Hodson SA and Wigham CG. Paracellular and Transcellular Water Diffusions Across Rabbit Corneal Endothelium. J Physiol 1987; 385: 89-96. 
${ }^{16}$ Hodson SA and Miller F. The Bicarbonate Ion Pump in the Endothelium Which Regulates the Hydration of Rabbit Cornea. J Physiol 1976; 263: 563-77.

${ }^{17}$ Mayers KR and Hodson SA. Some Effects of Hydrostatic Pressure on Corneal Hydration During Specular Microscopy. Exp Eye Res 1978; 26: $141-5$

${ }^{18}$ Hedbys BO and Mishima S. The thicknesshydration relationship of the cornea. Exp Eye Res 1963; 2: 99-111.

${ }^{19}$ Hodson and Williams (unpublished).

${ }^{20}$ Hodson, O'Leary and Watkins (unpublished).

${ }^{21}$ Sherrard ES and Buckley RJ. The relief mode: New application of the corneal specular microscope. Arch Ophthalmol 1982; 100: 296-300.

${ }^{22}$ Hartmann C. Die "indirekte" Spiegelmikroskopie: Eine neue Technik zur In vivo Untersuchung der Hornhautruckflache. Opthalmological (Basel) 1981; 183: 177-86.

${ }^{23}$ Sturrock GD, Sherrard ES, Rice NSC. Specular microscopy of the corneal endothelium. $\mathrm{Br} \mathrm{J}$ Ophthalmol 1978; 62: 809-14.

${ }^{24}$ Laing RA, Sandstrom MM, Berrospi AR, Leibowitz HM. Changes in the corneal endothelium as a function of age. Exp Eye Res 1976; 22: 587-94.

${ }^{25}$ Wilson RS and Roper-Hall MJ. Effect of age on the endothelial cell count in the normal eye. $\mathrm{Br} J$ Ophthalmol 1982; 66: 513-5.

${ }^{26}$ Hoffer KJ and Kraff MC. Normal endothelial cell count range. Ophthalmology 1980; 97: 861-6.

${ }^{27}$ Bigar F. Specular microscopy of the corneal endothelium. Dev Ophthalmol 1982; 6: 1-94.

${ }^{28}$ Sherrard ES, Novakovic P, Speedwell L. Agerelated changes of the corneal endothelium and stroma as seen in vivo by specular microscopy. Eye 1987; 1: 197-203.

${ }^{29}$ Speedwell L, Novakovic P, Sherrard ES, Taylor DSI. The infant corneal endothelium. Arch Ophthalmol (In press).

${ }^{30}$ Shaw EL, Rao GN, Arthur EJ, Aquavella JV. The functional reserve of the corneal endothelium. $\mathrm{Am}$ Acad Ophthalmol Otolaryngol 1978; 85: 640-9.

${ }^{31}$ Sherrard ES and Buckley RJ. Endothelial wrinkling - a complication of clinical specular microscopy. In Trevor-Roper P, ed. The Cornea in Health and Disease. Trans 6th Cong Euro Soc Ophthalmol 1981; 69-74.

32 Sherrard ES and Buckley RJ. Relocation of specific endothelial features with the clinical specular microscope. Br J Ophthalmol 1981; 65: 820-7.

${ }^{33}$ Sherrard ES, Frangoulis MA, Kerr Muir MG, Buckley RJ. The posterior surface of the cornea in the irido-corneal endothelial syndrome: a specular microscopial study. Trans Ophthalmol Soc UK 1985; 104: 766-74.
${ }^{34}$ Bourn WM. Partial corneal involvement in the iridicorneal endothelial syndrome. $A m \quad J$ Ophthalmol 1982; 94: 774-81.

${ }^{35}$ Neubauer L, Lund O-E and Leibowitz HM. Specular microscopic appearance of the corneal endothelium in iridocorneal endothelial syndrome. Arch Ophthalmol 1983; 101: 916-8.

${ }^{36}$ Cibis GW, Krachmer JH, Phelps CD, Weingeist TA. Iridocorneal adhesions in posterior polymorphous dystrophy. Trans Amer Acad Ophthalmol Otolaryngol 1976; 81: 770-7.

${ }^{37}$ Waring GO, Rodrigues MM, Laibson PR. Corneal dystrophies II. Endothelial dystrophies. Surv Ophthalmol 1978; 23: 147-68.

${ }^{38}$ Rodrigues MM, Sun TT, Krachmer J, Newsom D. Epithelialisation of the corneal endothelium in posterior polymorphous dystrophy. Invest Ophthalmol Vis Sci 1980; 19: 832-5.

${ }^{39}$ Laing RA, Leibowitz HM, Oak SS, Chang R, Berrospi AR, Theodore J-A. Endothelial mosaic in Fuchs' dystrophy. A qualitative evaluation with the specular microscope. Arch Ophthalmol 1981; 99: 80-3.

${ }^{40}$ Sherrard ES. The corneal endothelium in vivo: its response to mild trauma. Exp Eye Res 1976; 22: 347-57.

${ }^{41}$ Sherrard ES. Intraocular lens damage to the endothelium of in vitro rabbit cornea: a specular and scanning electron microscopial study. Trans Ophthalmol Soc UK 1983; 103: 565-76.

${ }^{42}$ Kerr Muir MG, Sherrard ES, Andrews V, Steele ADMcG. Air, methylcellulose, hyaluronate and the corneal endothelium. Eye 1987; 1: 480-6.

${ }^{43}$ Steele ADMcG, Buckley RJ, Sherrard ES. Early experiences with radial keratotomy. Trans Ophthalmol Soc UK 1982; 102: 35-41.

${ }^{44}$ Alfonso E, Tucker GS, Batlle JF, Mandelbaum S, Gelender H, Forster RK. Snail tracks of the corneal endothelium. Ophthalmology 1986; 93: 344-9.

${ }^{45}$ Laganowski HC, Kerr Muir MG, Sherrard ES. Postoperative grey-white lines of the posterior cornea and endothelial cell damage. $\mathrm{Br} J$ Ophthalmol 1987; 71: 877-83.

${ }^{46}$ Kerr Muir MG and Sherrard ES. Damage to the corneal endothelium during $\mathrm{Nd}$ : YAG laser photodisruption. $\mathrm{Br} J$ Ophthalmol 1985; 69: 77-85.

${ }^{47}$ Sherrard ES and Kerr Muir MG. Damage to the corneal endothelium by Q-switched $\mathrm{Nd}$ : YAG laser posterior capsulotomy. Trans Ophthalmol Soc UK 1985; 104: 524-8.

${ }^{48}$ Zantos SG and Holden BA. Transient endothelial changes soon after wearing soft contact lenses. Am J Optom Physiol Opt 1977; 54: 856-8.

${ }^{49}$ Kamiya C. A study of corneal endothelial response to contact lenses. Contact Lens 1982; 8: 92-5. 
${ }^{50}$ Buckley RJ. Transitory endothelial changes induced by soft contact lenses. In Henkind P, ed Acta: XXIV Internat Cong Ophthalmol Lippincott Co, Philadelphia.

${ }^{51}$ Khodadoust AA and Hirst LW. Diurnal variation in corneal endothelial morphology. Ophthalmology 1984; 91: 1125-8.

${ }^{52}$ Schoessler JP and Woloschak MJ. Corneal endothelium in veteran PMMA contact lens wearers. Int Contact Lens Clin 1981; 8: 19-25.

${ }_{53}$,MacRae SM, Matsuda M, Shellans S, Rich LF. The effects of hard and soft contact lenses on the corneal endothelium. Am J Ophthalmoi 1986; 102: 50-7.

${ }^{54}$ Stocker EG and Schoessler JP. Corneal endothelial polymegathism induced by PMMA contact lens wear. Invest Ophthalmol Vis Sci 1985; 26: 857-63.

${ }^{55}$ Schoessler JP, Barr JT, Frescon DR. Corneal endothelial observation of silicone elastomer in contact lens wearers. Internat Contact Lens Clin 1984; 11: 337-40.

${ }^{56}$ Carlson KH, Bourne WM, Brubaker RF. Effect of long-term contact lens wear on corneal endothelial cell morphology and function. Invest Ophthalmol Vis Sci 1988; 29: 185-93. 